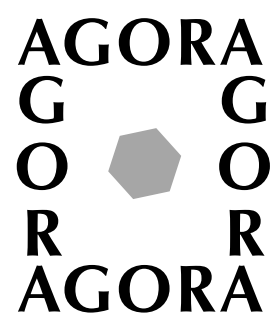

AGORA is a lighter channel of communication between readers and contributors; it aims to stimulate discussion and debate, particularly by presenting new ideas and by suggesting alternative interpretations to the more formal research papers published in WEB ECOLOgY and elsewhere. A lighter prose is encouraged and no summary is required. Formal research papers, however short, will not be considered.

\title{
Ecology, a science in the midst of society
}

\author{
Robert Barbault, Institut Fédératif d'Écologie Fondamentale et Appliquée (CNRS-FR3), Université \\ Pierre et Marie Curie 7, quai Saint Bernard, F-75252 Paris Cedex 05, France.
}

Contemporary societies, governments, individuals are all facing problems linked directly or indirectly to the functioning of ecological systems. Whatever the reason underlying these problems - be it the necessary use of biological resources, the elimination or recycling of wastes, our inevitable dependence on ecosystem services - neither politics nor ecology can afford to ignore them, and politicians and ecologists must learn to combine forces to solve them.

Beyond the banality of such a statement, already made clear by the emergence of green political parties, I would like to open the debate upon the revolutionary perspectives of bringing politics and ecology together, perspectives for ecology as a science and for environmental policies as social practices: basically, it is mankind that is called upon, even called into question.

Rather than emphasizing the possible contributions of ecology to solutions for the environmental problems of human societies, my purpose is to question the status of ecology and the behavior of ecologists at the cross-roads in the history of our science.

In fact, it is clear that most concepts or paradigms introduced and developed by ecologists appear crucial for anybody concerned with our identity and our future.

Moreover, one is struck by how most environmental problems faced by our contemporary society - pollution, degradation of our habitat, loss of biodiversity, the threats of climatic change, claims for a sustainable development constitute as many challenges to the science of ecology.

Is ecology, and are ecologists prepared for these challenges?

\section{A human-dominated planet}

Ecology as a science emerged together with our industrial society; a fact that has been widely overlooked throughout the modern phase of its establishment.

It was only in the last decades of the twentieth century that human societies were placed in the midst of ecology, by two world conferences marking a deep evolution in mind: 1) The United Nations Conference on Environment held at Stockholm in 1972, which marked a sudden awareness of environmental issues for most countries' governments and 2) The United Nations Conference on Environment and Development held at Rio de Janeiro in 1992, which emphasised, on the one hand, the key role and global responsibility of our species in the dynamics of the biosphere and, on the other hand, the dependence of our development on the health of our ecosystems.

In July 1997, the journal Science produced a special report on "Human Dominated Ecosystem".

In fact, human alteration of the earth's ecosystems is substantial and growing (Vitousek et al. 1986, 1997, Lubchenko et al. 1991, Vitousek 1994, Postel et al. 1996) - close to one-half of the land surfaces has been transformed by human actions - the carbon dioxide concentration in the atmosphere has increased by $30 \%$ since the beginning of the industrial revolution - more atmospheric nitrogen is fixed by humanity than by all natural terrestrial sources combined - humanity uses $54 \%$ of the freshwater runoff that is geographically and temporally accessible - more and more plant and animal species are driven to extinction. 
Some of these phenomena $\left(\mathrm{CO}_{2}\right.$ changes in the atmosphere, extinction of species) have been produced by natural causes in the past but they appear different nowadays, resulting from mankind's activities and taking place over a short period of time.

All of these changes alter the structure and function of Earth as an ecological system (Fig. 1). But, ultimately, all human-caused environmental changes are driven by the rapidly growing human population and our high rates of resource consumption (Vitousek 1994).

\section{About ecology}

The status of ecology as a science is nowadays well established. Various books retrace its history, pointing out its polyphyletic origins without questioning its deep rooting within natural sciences (Acot 1988, Deléage 1991, Drouin 1991).

But it is clear that, more than any other natural science, it also deals, directly or indirectly, with man and society.

Let me briefly recall the basic epistemological structure of modern ecology.
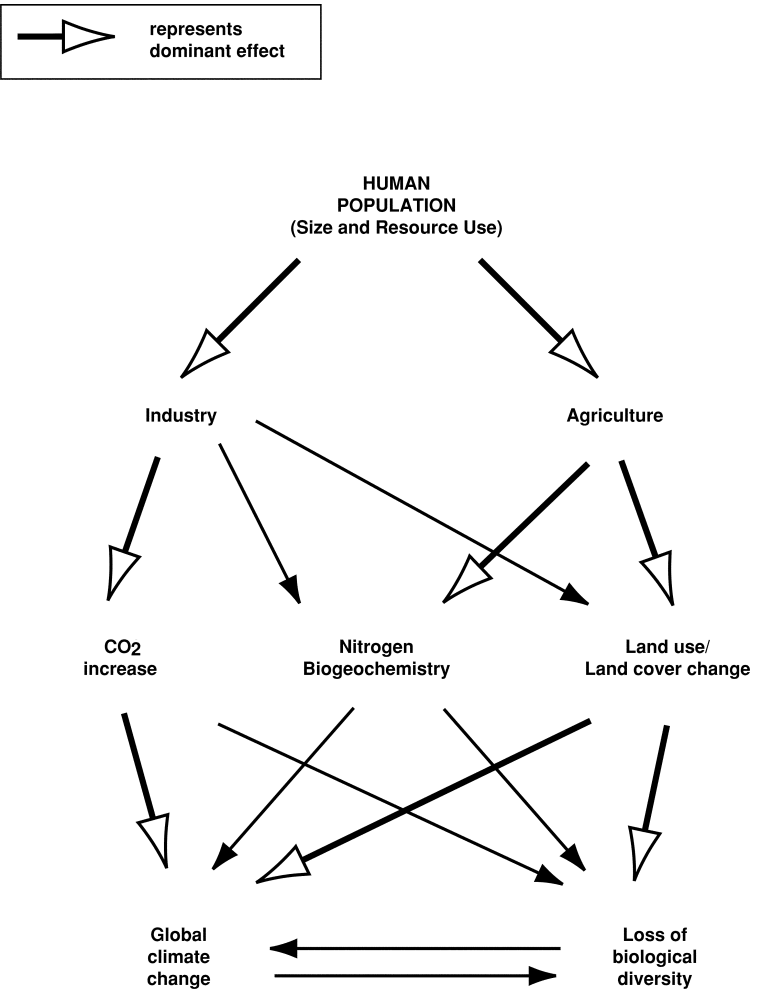

Fig. 1. The components of global environmental change emphasized in this paper. The wide arrows represent dominant effects (from Vitousek 1994).
Like any other science, ecology is characterised by the techniques and methods it develops (Legay and Barbault 1995) as well as by the kinds of mechanisms and phenomena it gives access to and that are not really grasped by other branches of biology (Fig. 2).

Although ecology, as a unified science rather than as a group of subdisciplines, can be questioned, I believe it is more relevant to defend the former point of view. Of course, for other purposes it might be preferable to take view that ecology is made up of a number of different subdisciplines. In fact, "Today, a unified ecology is more of a goal than a reality" (Dobson 1998).

To simplify, one can say that, beyond some polymorphism which constitutes its richness and beyond its strong connections with other disciplines, modern ecology is growing along two distinct, though overlapping main axes, one in the study of the dynamics and evolution of populations and communities, the other in that of dynamics and functioning of ecosystems and landscapes.

Let me underline that the objects of research in the latter - ecosystems, landscapes - are not exclusively biologi$\mathrm{cal}$. That makes a great difference if we consider that most ecologists are at first naturalists. Rather the interest rests on

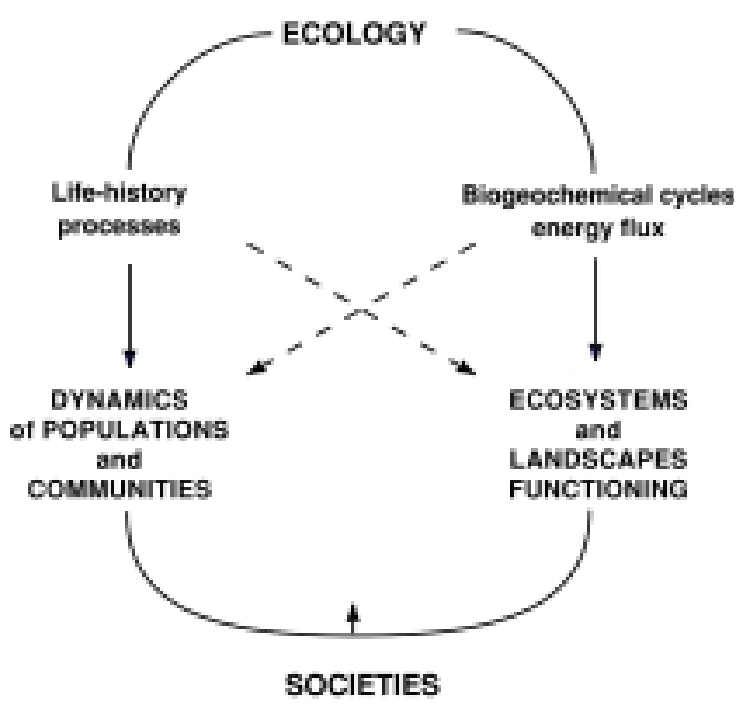

Fig. 2. Ecology, as a natural science, has for goal, on one side the analysis of life-history processes that work within populations and communities' dynamics, and, on the other side, the study of biogeochemical cycles and energy flows that structure ecosystems and lanscapes. Because human societies depend on and affect these cycles and processes, ecology is called to interact more and more with human sciences. 
processes and mechanisms involved in the cycles of nutrients and the flows of energy that allow ecosystems to function.

As a science of Nature, ecology has been blamed for having excluded man from its perspective, for turning away from areas he uses, from systems he manages or affects. It is true that ecologists have for a long time favoured a nature without man, mankind perceived as merely disturbing, as bringing disorder into nature (perceived as wilderness).

It is only fair, however, to make clear that, since the first significant developments of ecology at the end of the 19th and at the beginning of the 20th century, concerns about human society have been present. That Pearl, Lotka, Volterra turned their attention to the laws of growth of animal populations was, at least partly, due to their interests in the demographic and economic concerns raised by Thomas Malthus's essay on the Principle of population (1798). Let us neither forget that Wladimir Verdnarsky's essay on Biosphere, which emphasizes man's omnipresence in the functioning of the biosphere, was published in 1926.

More recently, the Ecological Society of America, through the Sustained Biosphere Initiative (Lubchenko et al. 1991) has come a long way towards being a professional policy voice for ecology.

Is it possible, so far, to define ecology as a social science, as did Jean-Paul Deléage (1991), subtitling his history of ecology "une science de l'homme et de la nature"?

Although we can speak about human ecology, urban ecology or economic ecology and even, more recently, about industrial ecology, these are truly new disciplines, because academic ecology did not, traditionally, make the human population one of his targets, to be included within ecological systems. It might be a grave omission, when human population growth gives rise to worries and controversies (Hardin 1993, Le Bras 1994, Cohen 1995).

In any case, ecology has to link with sociology, economics, psychology and geography. There is no advantage to appropriate them. It is clear that the disciplines dealing with mankind and his relationships with the environment are numerous. They do it in different perspectives, with their own questions. It is what makes multi-disciplinarity enriching.

Let us help ecology to keep its biological leadership and to claim its statute of science of nature, but let us recommend the establishment of links and exchanges with other sciences wherever the questions to deal with need it!

\section{From ecology to politics}

Ecology is being confronted by politics more and more frequently. But such an interface is delicate, even dangerous because it is indirect, unavoidable and it is not restricted to such a simple pairing.

In fact, there is no direct relationship between the sci- ence of ecology and politics: it is regarding environmental problems that ecology and politics meet; both are required and called upon, but separately (Fig. 3). The confusion maintained by the word ecology, used in many countries to qualify green parties as well as environmental problems, is particularly harmful for our science and the building of clear democratic debates regarding issues of concern for ecologists, green militants, decision makers... and laymen.

It is harmful for ecology as a science because it pushes it, in some way, to withdraw into itself in order to escape from the trap of the "mediasation" and from thereby unavoidable discredit.

Yet, between the science and the society, debate is inescapable, and ecologists as scientists must become involved in it. But not alone. Not without preparation.

It is clear that Fig. 3 gives only a partial picture of the real situation.

Regarding its approaches of environmental problems, ecology is necessarily faced with other problems than what it can legitimately deal with: other competences must be mobilised to solve them.

The intellectual space covered by ecology confronts it with, on the one hand, the sciences of mankind and society and on the other hand with the earth sciences. As an aside, these two interfaces are in fact a bit different: between ecological sciences and earth sciences there is no discontinuity, no need for an epistemological jump, quite in contrast to the difference between natural and human sciences.

In fact the opening to the society leads to a delicate confrontation, far from the comfortable protection offered by the position of an objective science: we are entering into the fields of psychology, of philosophy and of course of policy. While researchers in human sciences have for a long time been aware of this, and are used to behaving accord-

\section{Earth Sciences}

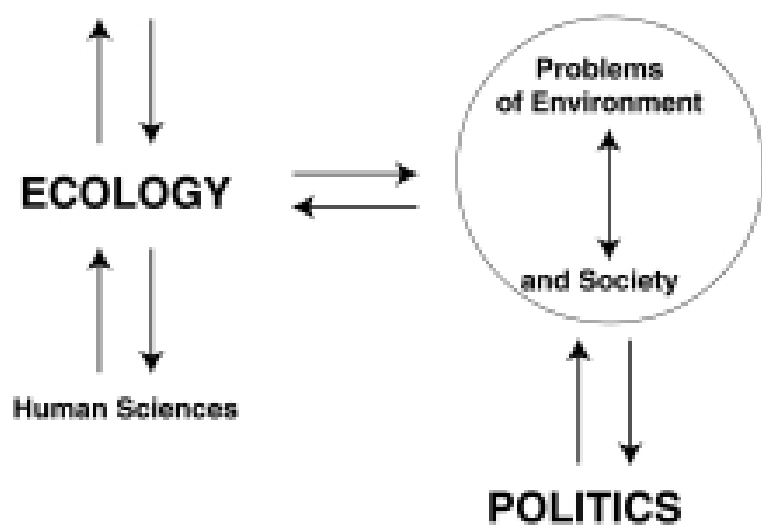

Fig. 3. The meeting between ecology and politics occurs around environment problems - that is society questions. When tackling environmental issues ecology is necessarly confronted to human sciences and has also to take profit of competences bring up by earth sciences. 
ingly, it has only recently been recognized and acknowledged by ecologists. In ecology as well as in other "hard" sciences, everyone is faced only by himself, free to continue on the path or not, to jump or to stay in his "ivory tower". Such personal commitment must be decided on consciously, aware of the consequences for the development of our science and for our duty as scientists - which includes diffusion of knowledge, openness to questioning by society, and contributing to the culture. Ecologists, as all scientists, must be concerned about the use that society makes of their science, even if they cannot control the process. One cannot, on the one hand, justify one's research by its relevance for society, but on the other hand turn a deaf ear to the needs of society.

The contributions of ecology to the welfare of our society and culture must be increased: an ecological way of thinking is spreading, whether ecologists want it or not, but this influence is still rather diffuse and must become expressed more clearly, debated, and brought to the level of citizens.

\section{Ecology and ecological thinking}

Ecology pervades the thinking of many contemporaneous philosophers and sociologists. Thus, in his bulky essay entitled La Méthode, Edgar Morin devotes one full volume, La Vie de la Vie (1980), explicitly to ecology. Ecologists have been standing aside from this kind of development, most often because of their ignorance, but also as a precaution in face of the risk of confusion, of insidious shifts on political grounds.

Today more than ever, scientists are facing a dilemma: to remain quiet but isolated within the ivory tower of science or to balance on the shifting grounds of societal demands, at risk of being manipulated by political pressures. In fact, it is no longer possible to ignore the social, political and philosophical dimensions of science in any scientific field. Science is a product of society. It needs the support of the society to mature. It is influenced by social background, but in turn can and should influence society.

Moreover, it is clear that an ecological way of thinking is maturing, for instance into a phenomenon that does not touch physical or chemical sciences. I do not know if Hans Jonas can be considered as an ecological philosopher, but what is certain is that his book Responsibility principle (1979) has greatly influenced Green thinking and society in Germany. He emphasizes the urgency for a radical change in the role of science and technology in western societies. He argues that scientific and technical progress can be dangerous far beyond the military fallout, through its consequences to the global equilibria of the biosphere and the integrity of mankind. For Hans Jonas, sciences and technology threaten the quality of our life, or even the survival of our future generations.

At the same time, a diffuse distrust against science, against its pretentiousness and possible diversions is expanding (Maddox 1995, Testart 1995, Boy 1999, Haerlin and Parr 1999). Even if ecological science is not the main focus of this movement, it is certainly particularly exposed.

As phrased by Jacques Testart (1995), any criticism aimed at "technoscience" (he uses that word to pinpoint the intricacies of both the scientific and technological production resulting from market pressures) gives a pretext for virulent retorts. Thus, he writes: "The Heidelberg call issued on the occasion of the 1992 Earth Summit in Rio by 236 scientists, of whom 52 are winners of the Nobel Prize, praises the credo of science in order to counter-attack the vague desires to control science expressed by some researchers or associations with ecological orientations". Indeed, this manifest of scientific imperialism demands even more power for technoscientific activity, supposedly the only activity that is capable of solving the problems of the world. One can spot two arguments repeated over and over again in this kind of plea. The first stigmatises any criticism of science as based on an "irrational ideology", thus confusing a kind of ecological extremism (which would prefer to sacrifice man to nature) with humanitarian lucidity (which refuses to sacrifice man to technoscience). The second argument maintains that the solutions to the great threats to our planet demand more technoscience, thus sweeping aside on the one hand the responsibility of the technical progress itself in causing the problems and on the other hand the shortcomings of politics in managing the technology already available to diminish some of the problems faced by mankind.

Scientists must learn to call themselves into question and to open up to the rest of society, if they want to counter these dangerous claims, as called to our attention by Testart (1995), and if they want to avoid that science is rejected by a growing number of people. At the same time, scientists must emphasize the difference between science and the utilisation of science. Beyond the clarifying and ethical aspects, this warning raises the more general question of knowledge transfer.

\section{The revolutionary virtue of ecology}

One of the major contributions of ecology to our society, apart from increasing our knowledge about the structure and dynamics of the biosphere, should be within the field of culture. There is an ecological way of thinking about the world, about the place of mankind in the world. Yes indeed, it is also mankind that is dealt with by ecology: man as a biological being, man as a species that depends on the functioning of ecosystems, man as a species that is responsible for its future.

It would be easy to show the potentially revolutionary content of most concepts or paradigms of ecology: the theory of evolution by natural selection; the biological concept of populations; life-history theory; the theory of eco- 
logical niches; the concept of ecosystems with its series of direct and indirect interactions of feedbacks and delayed effects; the concepts of recycling of nutrients, of ecological succession, of resilience; the concept of biodiversity.

But let us consider only, as an example, the concept of biodiversity.

The word biodiversity (coined by Walter G. Rosen in 1985 for the first National Forum on Biodiversity held in Washington D.C. in September 1986 - of which proceedings were published by Wilson and Peter in 1988) is a simple abbreviation for biological diversity. Nothing novel in this, it may seem. But the success of this verbal mutation, which rapidly invaded not only the specialised literature but also ecological and political discussions, reveals a change in mind, an evolutionary jump, the birth of the new concept. One can even date its "venue au monde": June 1992. In fact, it was at the United Nations Conference for the Environment and the Development, the Earth Summit of Rio, that biological diversity left its naturalist niche to question Mankind, while concerns about its conservation continued to grow and confront the inordinate desire to exploit it.

Apart from considering the genetic variability, the species richness of faunas and floras or the role of ecological diversity on the functioning of ecosystems, the true target, the ultimate interest or concern is mankind, it is man that threatens biological diversity, it is man that desires it, it is man that depends on it for the development of society or even survival, it is man that is one of its manifestations.

Thus, with a classic ecological approach, the recent literature about these issues emphasizes: 1) the value of biological diversity as a "reservoir" of molecules of pharmaceutical interest, of food, of industrial materials i.e. its status as a biological resource, 2) the idea that ecosystems provide not only biological resources, but also ecological services, the regulation of the water cycle and biogeochemical cycles, the recycling of organic matter, the dampening of climate changes, etc., 3) the importance of biological diversity for the resilience of ecosystems i.e. their ability to recover after perturbation, their long-term persistence.

Thus, progressively, the ecological analyses are switching to the role of human societies in the dynamics of biodiversity, be it through their uses of biological resources, their degradation of ecosystems or their management of landscapes.

Ecology is progressively leaving purely "ecological" problems to deal with considerations pertaining to social sciences, economy, etc. and is moving into problems of the society - conflicts of interests, immediate versus long-term goals, needs of choice.

In other words, two epistemological breaks emerge from this logical process: the first is in the move to socio-economic approaches; this calls for a broadening of the classical concept of ecosystem in order to link it with economic systems. The second lies in the extrapolation from a purely scientific discipline to philosophical or political grounds.
One can no longer neglect to take into account a socioecological-economic framework in tackling the problems raised by the dynamics of biodiversity. I agree with Barbier et al. (1994) when they suggest to superpose and link ecological systems and economic systems as schematised in Fig. 4. This is the first epistemological jump academic ecologists will have to accept.

Furthermore, what brings with it the revolutionary potential of a true ecological way of thinking results from simply being aware of the strong involvement of man in the current debates about biodiversity.

In fact, as I mentioned above, any ecological reflection about biodiversity dynamics leads to mankind: 1) to mankind as a biological being, product of evolution and one manifestation among many others of the diversity of life, 2) to mankind as a species, depending directly and indirectly on a plethora of other species it threatens, 3 ) to mankind as a producer of values, of civilizations, as a human being confronted with his global responsibility towards future generations.

Such a projection onto political and philosophical grounds concerns every citizen, and in particular also the scientists. A citizen who calls for a public debate, who is concerned about the goals of our society.

\section{Conclusion}

For ecology as a science the danger is clear. To refuse the challenge is to lose any social legitimacy: research is costly for the society that accepts it. Here also choices have to be taken; here also a public debate is needed.

On the other side, entering thoughtlessly into the debate, with vague objectives and motivations, can discredit science and the scientific knowledge and practices that are necessary for the debates that are only just starting.

Yes, ecology is basically a science about nature but including human nature. A science challenged by decisive stakes for the future of our society and species.

As a cultural being, mankind has to take up the challenge of managing the biosphere to ensure a sustainable development, here and elsewhere, today and tomorrow - a challenge to civilization.

As emphasized by Vitousek et al. (1997) "Recognition of the global consequences of the human enterprise suggests three complementary directions. First, we can work to reduce... the rate at which we alter the system Earth... Second, we can accelerate our efforts to understand Earth's ecosystems and how they interact with numerous components of human-caused global change... Finally, humanity's dominance of Earth means that we cannot escape the responsibility for managing the planet". 


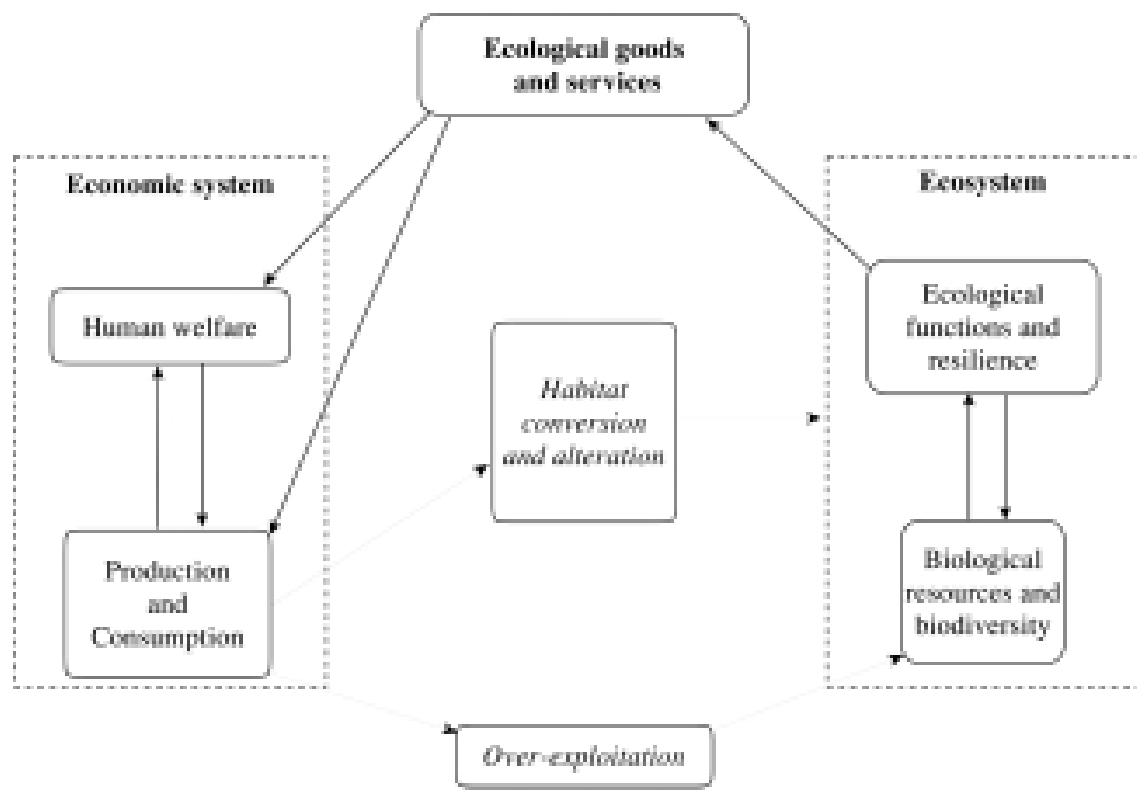

Fig. 4. Economic environmental linkages associated with biodiversity loss (from Barbier et al. 1994).

\section{References}

Acot, P. 1988. Histoire de l'écologie. - PUF, Paris.

Barbier, E. B., Burgess, J. C. and Folke, C. 1994. Paradise lost? The ecological economics of biodiversity. - Earthscan, London.

Boy, D. 1999. Le progrès en procès. - Presse de la Renaissance, Paris.

Cohen, J. E. 1995. How many people can the earth support? W. W. Norton and Company, New York.

Deléage, J. P. 1991. Histoire de l'écologie. Une science de l'homme et de la nature. - La Découverte, Paris.

Dobson, S. I. 1998. Ecology. - Oxford Univ. Press.

Drouin, J. M. 1991. Réinventer la nature. L'écologie et son histoire. - Desclée de Brouwer, Paris.

Haerlin, B. and Parr, D. 1999. How to restore public trust in science. - Nature 400: 499.

Hardin, G. 1993. Living within limits. Ecology, economics and population taboos. - Oxford Univ. Press.

Jonas, H. 1979. Le Principe responsabilité. Une éthique pour la civilisation technologique. - Editions de Cerf, Paris.

Le Bras, H. 1994. Les limites de la planète. Mythes de la nature et de la population. - Flammarion, Paris.

Legay, J. M. and Barbault, R. 1995. La révolution technologique en écologie. - Masson, Paris.

Lubchenco, J. et al. 1991. The sustainable biosphere initiative: an ecological research agenda. - Ecology 72: 371-412.

Maddox, J. 1995. The prevalent distrust of science. - Nature 378: 435-437.

Malthus, T. R. 1798. An essay on the principle of population. Trad. fr. Essai sur le principe de population. Gauthier, 1963, Paris.

Morin, E. 1980. La Méthode, Tome II: La Vie de la Vie. - Editions du Seuil, Paris.

Postel, S. L., Daily, G. C. and Ehrlich, P. R. 1996. Human appropriation of renewable fresh water. - Science 271: 785-787.

Testart, J. 1995. Logique propre de la science et progrès humain. - In: Droit, R. P. (ed.), L'avenir aujourd'hui dépend-il de nous? Le Monde Éditions, Paris, pp. 196-215.

Vitousek, P. M. 1994. Beyond global warming: ecology and global change. - Ecology 75: 1861-1876.

Vitousek, P. M. et al. 1986. Human appropriation of the products of photosynthesis. - Bioscience 36: 368-373.

Vitousek, P. M. et al. 1997. Human domination of earth's ecosystems. - Science 277: 494-499.

Wilson, E. O. and Peter, F. M. 1988. Biodiversity. - Natl. Acad. Press, Washington, D.C. 